\title{
Linc01234 promotes cell proliferation and metastasis in oral squamous cell carcinoma via miR-433/PAK4 axis
}

\author{
Deyu Liu', Xinchun Jian ${ }^{1,2^{*}} \mathbb{D}, \mathrm{Pu} \mathrm{Xu}^{1 *}$, Rong Zhu ${ }^{1}$ and Yuan Wang ${ }^{3}$
}

\begin{abstract}
Background: Increasing studies have demonstrated that long non-coding RNAs (IncRNAs) play an important role in tumor progression. However, the potential biological functions and clinical importance of Linc01234 in oral squamous cell carcinoma (OSCC) remain unclear.

Methods: We evaluated the expression profile and prognostic value of Linc01234 in OSCC tissues by RT-qPCR. Then, functional in vitro experiments were performed to investigate the effects of Linc01234 on tumor growth, migration and invasion in OSCC. Mechanistically, RT-qPCR, bioinformatic analysis and dual luciferase reporter assays were performed to identify a competitive endogenous RNA (ceRNA) mechanism involving Linc01234, miR-433-3p and PAK4.

Results: We found that Linc01234 was clearly upregulated in OSCC tissues and cell lines, and its level was positively associated with T stage, lymph node metastasis, differentiation and poor prognosis of patients with OSCC. Our results shown that Linc01234 inhibited cell proliferation and metastatic abilities in CAL27 and SCC25 cells following its knockdown. Mechanistic analysis indicated that Linc01234 may act as a ceRNA (competing endogenous RNA) of miR-433-3p to relieve the repressive effect of miR-433-3p on its target PAK4.
\end{abstract}

Conclusions: Our results indicated that Linc01234 promotes OSCC progression through the Linc01234/miR-433/ PAK4 axis and might be a potential therapeutic target for OSCC.

Keywords: OSCC, Linc01234, miR-433, PAK4, ceRNA

\section{Background}

Oral squamous cell carcinoma (OSCC) is one of the most prevalent subsets of head and neck cancers, ranking as the eighth most common cancer among all malignant tumors worldwide [1]. A new global cancer statistic in 2018 reported that 447,751 newly diagnosed cases of oral cancer and oropharyngeal tumors worldwide [2]. Although new technologies in diagnosis and treatment have greatly improved the overall survival rates, the prognosis of OSCC still remains dismal [3]. Therefore, it's necessary to explore the underlying mechanism and provide novel therapeutic targets for OSCC.

\footnotetext{
* Correspondence: jian_xinchun@163.com; hnxupu@163.com

'Department of Oral and Maxillofacial Surgery, Affiliated Haikou Hospital, Xiangya Medical College, Central South University, Haikou 570208, China Full list of author information is available at the end of the article
}

Recently, it has been verified that long noncoding RNAs (lncRNAs) function as oncogenes or tumor suppressors to regulate the biological behaviors of diverse neoplasms $[4,5]$. At present, numerous studies have confirmed that lncRNAs are involved in cell proliferation, apoptosis, migration and metabolism in OSCC [6]. For example, IncRNA LEF1-AS1 is remarkedly upregulated in OSCC tissues and servs as an oncogene in OSCC by suppressing the Hippo signaling pathway [7]. LncRNA MEG3 exerted an antitumor effect on cell growth and metastasis in OSCC by suppressing the activity of the $\mathrm{WNT} / \beta$-catenin pathway [8]. In addition, aberrant lncRNAs also serve as prognostic indicators for tumor recurrence and metastasis. For example, SNHG15 was reported to be significantly upregulated in tumors and enhanced SNHG15 expression could be a promising biomarker for cancer diagnosis, prognosis or treatment [9].

(C) The Author(s). 2020 Open Access This article is distributed under the terms of the Creative Commons Attribution 4.0 International License (http://creativecommons.org/licenses/by/4.0/), which permits unrestricted use, distribution, and reproduction in any medium, provided you give appropriate credit to the original author(s) and the source, provide a link to the Creative Commons license, and indicate if changes were made. The Creative Commons Public Domain Dedication waiver (http://creativecommons.org/publicdomain/zero/1.0/) applies to the data made available in this article, unless otherwise stated. 
However, the detailed biological importance of most lncRNAs in OSCC development remains unclear.

Linc01234 (ENSG00000249550) is a conserved lncRNA located at $12 \mathrm{q} 24.13$ that is aberrantly expressed in several cancers [10-12]. Linc01234 was closely correlated with poor survival in OSCC and breast cancer through analyses of the TCGA database [13, 14]. Although Linc01234 has been reported as an oncogene promoting OSCC growth and inhibiting apoptosis [11], the clinical importance and underlying mechanism of Linc01234 in OSCC progression is still unclear.

Here, our study was conducted to examine the expression levels of Linc01234 in clinical OSCC samples and a series of OSCC cell lines. Then, we investigated the effects of Linc01234 on cell proliferation and migration in OSCC through gain-of-function and loss-of-function experiments. The present study also analyzed the association between Linc01234 expression and the clinical features and prognosis of OSCC patients and might provide new light on targeted therapy and the diagnosis of oral cancer.

\section{Methods}

\section{Clinical specimens of OSCC}

Eighty-eight pairs of OSCC samples were randomly collected from OSCC patients who underwent surgery at the Affiliated Haikou Hospital and Xiangya Hospital, Central South University from 2012 to 2014. None of OSCC patients received radio- or chemotherapy before their surgery. All tumor tissues and their adjacent noncancerous tissues were immediately frozen stored in liquid nitrogen for subsequent RNA extraction. This study was approved by the Ethics Committee of Affiliated Haikou Hospital and Xiangya Hospital, and all OSCC patients provided the informed consent.

\section{Cell culture}

The CAL27(ATCC ${ }^{\oplus}$ CRL-2095), SCC9(ATCC ${ }^{\circledast}$ CRL-1629) and SCC25(ATCC ${ }^{\ominus}$ CRL-1628) cell lines were obtained from American Type Culture Collection (Manassas, VA, USA), The HSC3, NOK and CAL33 cell lines were kindly gifted from Guanghua School of Stomatology of Sun yetsan University. CAL27, CAL33 and HSC3 cells were cultured in DMEM (Gibco, NY, USA) supplemented with 10\% FBS (Invitrogen, Carlsbad, CA, USA). SCC25 and SCC9 cells were cultured in DMEM/F-12 (Gibco, NY, USA) supplemented with $10 \%$ FBS. Normal oral keratinocytes (NOKs) were cultured in KSFM (Gibco, NY, USA) supplemented with EGF. All cell lines were cultured in a $37^{\circ} \mathrm{C}, 5 \% \mathrm{CO}_{2}$ incubator (Additional file 4: Figure S4).

\section{Cell transfection}

Linc01234 siRNAs and control siRNAs were purchased from RiboBio (Guangzhou, China). CAL27 and SCC25 cells were seeded in the 6-well plate and added with $5 \mu \mathrm{L}$ of siRNAs or siNCs $(50 \mathrm{nM})$ and $5 \mu \mathrm{L}$ of Lipofectamine 2000 (Invitrogen, Carlsbad, USA) in each well following the manufacturers' instructions.

Subcellular fraction and real-time quantitative PCR (RT-qPCR) The PARIS Kit purchased from Invitrogen (Carlsbad, CA, USA) was applied to isolate cytoplasmic and nuclear RNAs using a previously established protocol, followed by RTqPCR detection [15]. Total RNA from OSCC tissues and cells was collected using the TRIzol Reagent (Invitrogen Life Technologies) and was subsequently reverse transcribed to cDNA using the PrimeScript RT reagent Kit (Takara, Tokyo, Japan). RT-qPCR detection was performed on a Roche LightCycler 480 system (Bio-Rad, Hercules, CA, USA) using a SYBR Green qPCR Mix (Takara). The relative RNA expression was calculated using the $\left(2^{-\Delta \Delta C t}\right)$ method. The $\Delta \mathrm{Ct}$ values were normalized to these of GAPDH or U6.

\section{EdU assay}

After $48 \mathrm{~h}$ transfection, CAL27 and SCC25 cells $\left(2 \times 10^{4} /\right.$ well) were seeded in 24-well plates. The 5-ethynyl-2'deoxyuridine (EdU) assay (Life Technologies Corporation, USA) was used to evaluate the proliferation ability of OSCC cells as previously reported [16]. Briefly, CAL27 and SCC25 cells were incubated with $100 \mu \mathrm{L}$ EdU reagent for $2 \mathrm{~h}$ at $37^{\circ} \mathrm{C}$, and stained with DAPI and visualized by a fluorescence microscope (Olympus, Tokyo, Japan).

\section{Cell counting Kit-8 (CCK-8) assay}

CAL27 and SCC25 cells were cultured in 96-well plates at 8000cells/well after transfection. Following the 4 consecutive days culture, each well was replaced by the fresh medium containing 10\% CCK-8 solution (Yeasen, Shanghai, China). After a $2 \mathrm{~h}$ incubation at $37^{\circ} \mathrm{C}$, the absorbance of $450 \mathrm{~nm}$ was measured using a microplate reader (Bio-Rad, Hercules, CA, USA).

\section{Transwell assays}

The migration and invasion ability were assessed using Transwell chamber with $8 \mu \mathrm{m}$ pore (Corning, New York, NY, USA). To evaluate the invasion capacity, OSCC cells $\left(1 \times 10^{5}\right)$ suspended in serum-free DMEM were added into the upper chamber precoated with Matrigel matrix (BD Biosciences, San Jose, CA, USA). For migration assay, OSCC cells $\left(1 \times 10^{5}\right)$ were cultured in the Boyden chamber without Matrigel. After $24 \mathrm{~h}$ incubation, the migrated and invaded cells were fixed and stained, and counted under a microscope (Leica, Wetzlar, Germany).

\section{Wound-healing assays}

CAL27 and SCC25 cells were seeded in the 6-well plate and transfected with siRNAs or siNCs. Until a $90 \%$ 
confluence, we generated a scratch on the bottom of each well. After washing with PBS, cells were photographed using a microscope (Leica, Wetzlar, Germany) at $0 \mathrm{~h}$ and $48 \mathrm{~h}$.

\section{Dual-luciferase reporter assays}

The sequence of Linc01234 or PAK4 3'-UTR containing the putative or mutated binding sites for miR-433-3p were cloned into the pMIR-REPORT vector (Promega, Madison, WI, USA). The wild-type or mutant pMIR-REPORT vectors were co-transfected into CAL27 and SCC25 cells as long with miR-433-3p mimics and miR-NC. Fourtyeight hour later, the relative luciferase activity was assessed using a dual luciferase assay kit (Promega) and these values were normalized to Renilla activity.

\section{Western blot assays}

Total protein from CAL27 and SCC25 cells was lysed in RIPA buffer (Beyotime, China). Then, the lysates were treated with a 10\% SDS-PAGE gel and transferred onto PVDF membranes (Millipore Corporation, USA). After $1 \mathrm{~h}$ incubation in 5\% nonfat milk solution, the PVDF membranes were cultured with anti-PAK4 (ab62509, Abcam, Cambridge, $\mathrm{UK}$ ) and anti-GAPDH (AC003, ABclonal, China) antibodies overnight at $4{ }^{\circ} \mathrm{C}$. After TBST washing, the membranes were incubated with the matched secondary antibodies (Proteintech, wuhan, China) at $37^{\circ} \mathrm{C}$ for $1 \mathrm{~h}$. The reaction was visualized by an enhanced chemiluminescence (ECL) detection system (Millipore, MA, USA).

\section{Statistical analysis}

All data in this study were performed with SPSS 22.0 (IBM Corp., Armonk, NY, USA) and were expressed as the mean \pm standard deviation of at least three independent experiments. CCK8 experiments, colony formation assay, Transwell, wound-healing and dual-luciferase reporter assays, RT-qPCR and Western blotting, were each independently repeated 3 times. Comparisons were performed using two-tailed Student's $t$-test or one-way ANOVA. The correlation between Linc01234 expression and clinicopathological parameters was analyzed using the $\chi^{2}$ test. $P<0.05$ was considered to indicate a statistically significant difference.

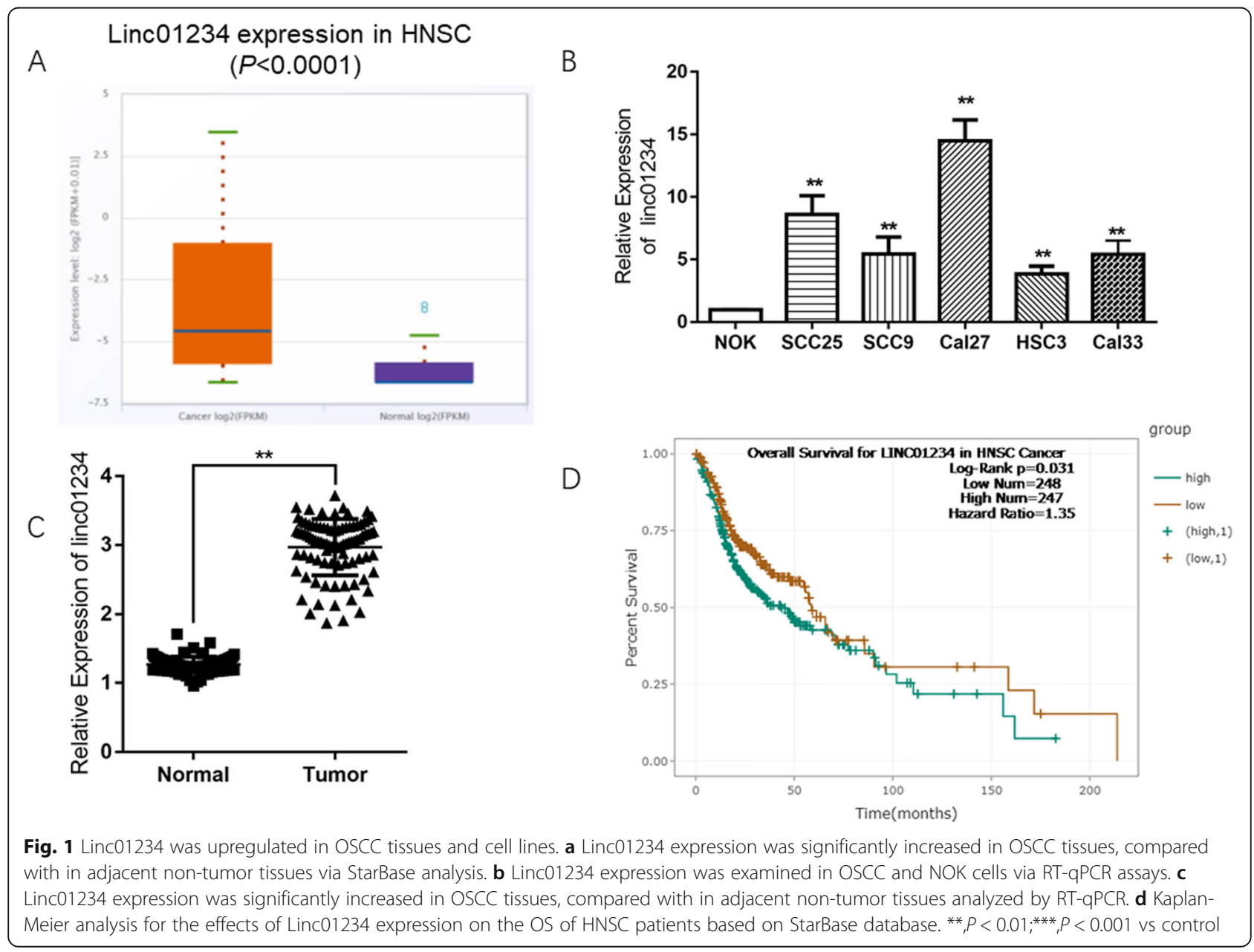


Table 1 The association between linc01234 expression and clinicopathological parameters in patients with OSCC

\begin{tabular}{|c|c|c|c|c|}
\hline \multirow{2}{*}{$\begin{array}{l}\text { Clinicopathological } \\
\text { parameters }\end{array}$} & \multicolumn{2}{|c|}{ Linc01234 expression } & \multirow[t]{2}{*}{$x^{2}$} & \multirow[t]{2}{*}{$P$ value } \\
\hline & $\operatorname{Low}(N=44)$ & $\operatorname{High}(N=44)$ & & \\
\hline Age & & & 0.16 & 0.665 \\
\hline$<60$ & 27 & 25 & & \\
\hline$\geq 60$ & 17 & 19 & & \\
\hline Gender & & & 0.05 & 0.829 \\
\hline Male & 25 & 26 & & \\
\hline Female & 19 & 18 & & \\
\hline Tumor site & & & 0.18 & 0.669 \\
\hline Tongue & 22 & 24 & & \\
\hline Non-tongue & 22 & 20 & & \\
\hline T stage & & & 9.08 & 0.002 \\
\hline $\mathrm{T}_{1-2}$ & 32 & 18 & & \\
\hline$T_{3-4}$ & 12 & 26 & & \\
\hline Lymphnode metastasis & & & 3.93 & 0.048 \\
\hline No & 32 & 23 & & \\
\hline Yes & 12 & 21 & & \\
\hline Distance metastasis & & & 0.72 & 0.395 \\
\hline Yes & 6 & 9 & & \\
\hline No & 38 & 35 & & \\
\hline \multicolumn{5}{|l|}{ Differentiation } \\
\hline Well and moderately & 34 & 26 & 4.87 & 0.027 \\
\hline Poorly & 8 & 18 & & \\
\hline
\end{tabular}

\section{Results}

Linc01234 is increased in OSCC tissues and cell lines

To explore the expression value and clinical significance of Linc01234 in OSCC, we first examined the levels of Linc01234 in the starBase database and specimens collected at our hospitals. As shown in ure 1A, Linc01234 was dramatically upregulated in HNSC samples (Cancer) compared with normal tissues (Normal) $(P<0.0001)$. We further detected the expression levels of Linc01234 in 88 OSCC specimens and adjacent oral normal tissues, which were collected from surgical resection at Affiliated Haikou Hospital and Xiangya Hospital. The RT-qPCR results indicated that the mRNA levels of Linc01234 in OSCC tissues were significantly higher than those in adjacent nontumor tissues $(P<0.01$; Fig. 1c). Following culture of four OSCC cell lines and the negaFigtive control NOK cells, Linc01234 expression was found to be significantly increased in all OSCC cell lines $(P<0.05$; Fig. 1b), compared with the NOK cell line.

\section{Linc01234 is closely associated with OSCC patient prognosis}

To investigate the clinical significance of Linc01234 in OSCC progression, the association between Linc01234 expression and clinicopathological features was analyzed by the $\chi^{2}$ test. We found that Linc01234 expression was closely correlated with $\mathrm{T}$ stage, $\mathrm{N}$ stage and pathological stage $(P<0.05)$, however there was no statistical significance between Linc01234 and age, gender, tumor site or distant metastasis (Table 1). In addition, Cox analysis shown that Linc01234 expression could be an independent predictor of OSCC patient prognosis as well as $\mathrm{T}$ stage, $\mathrm{N}$ stage and advanced pathological stage (Table 2), indicating that Linc01234 could be an independent prognostic factor for OSCC with an aggressive phenotype. In addition, the starBase database analysis shown that high expression of Linc01234 in head and neck cancer patients was closely correlated with short overall survival (OS) (Fig. 1d).

\section{Silencing Linc01234 represses OSCC cell growth}

To explore the biological role of Linc01234 in OSCC, we transfected siRNAs targeting Linc01234 in CAL27 and SCC25 cells and examined Linc01234 levels by RT-qPCR. Following transfection, the siRNAs clearly decreased the transcription of Linc01234 in CAL27 and SCC25 cells (Fig. 2a), suggesting a high knockdown efficiency of these siRNAs. Using CCK8 assays, the proliferative rates were shown to be significantly decreased by Linc 01234 inhibition in CAL27 cells and SCC25 cells (Fig. 2b). Furthermore,

Table 2 Univariate and multivariate Cox proportional hazards analysis of linc01234 expression and OS in patients with OSCC

\begin{tabular}{|c|c|c|c|c|}
\hline \multirow{2}{*}{$\begin{array}{l}\text { Clinicopathological } \\
\text { parameters }\end{array}$} & \multicolumn{2}{|c|}{ Univariate Cox analysis } & \multicolumn{2}{|c|}{ Multivariate Cox analysis } \\
\hline & $\overline{\mathrm{RR}}(95 \% \mathrm{Cl})$ & $P$ value & $\overline{\mathrm{RR}}(95 \% \mathrm{Cl})$ & $P$ value \\
\hline Age & $0.91(0.43-1.77)$ & 0.588 & & \\
\hline Gender & $1.04(0.65-1.51)$ & 0.903 & & \\
\hline Tumor site & $1.15(0.98-1.35)$ & 0.094 & & \\
\hline T stage & $1.72(1.18-2.26)$ & 0.020 & $1.82(1.42-2.94)$ & 0.003 \\
\hline Lymphnode metastasis & $1.41(1.11-1.92)$ & 0.036 & $1.52(1.05-1.86)$ & 0.031 \\
\hline Distance metastasis & $0.95(0.61-1.47)$ & 0.834 & & \\
\hline Differentiation & $1.44(1.18-1.82)$ & 0.010 & $1.15(1.02-1.30)$ & 0.028 \\
\hline Linc01234 expression & $1.64(1.38-2.55)$ & 0.008 & $1.99(1.33-3.05)$ & 0.001 \\
\hline
\end{tabular}




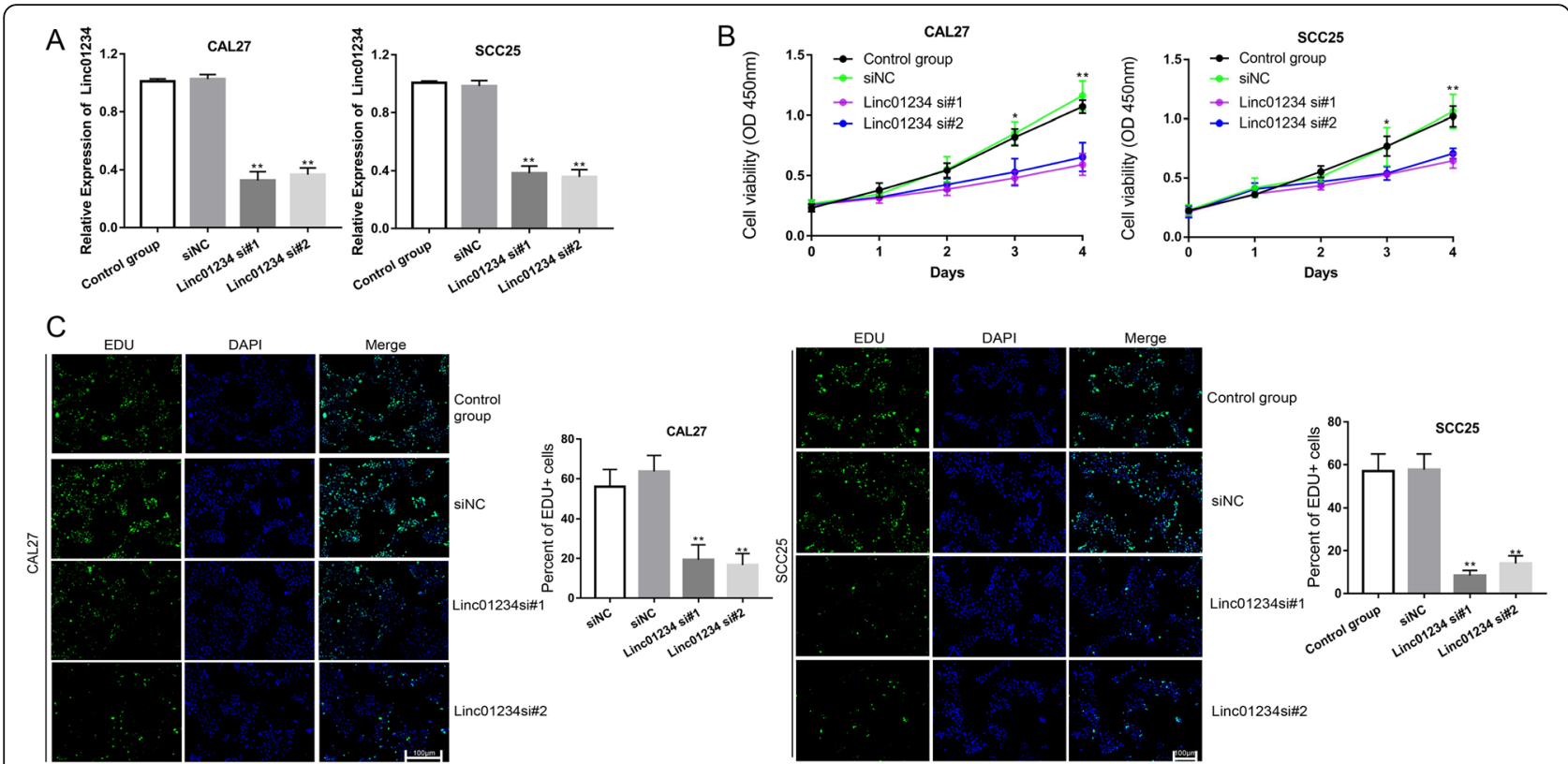

Fig. 2 Decreased Linc01234 inhibits cell proliferation in vitro. a The relative expression of Linc01234 was detected with RT-qPCR when CAL27 and SCC25 cells were transfected with siNC, Linc01234 si\#1 or Linc01234 si\#2. b CCK8 assays were performed to detect the cell proliferation ability after CAL27 and SCC25 cells transfected with siNC, Linc01234 si\#1 or Linc01234 si\#2. c EDU assays were performed to detect the cell proliferation ability in CAL27 and SCC25 cells transfected with siNC, Linc01234 si\#1 or Linc01234 si\#2. ${ }^{*} P<0.05 ;{ }^{*}, P<0.01$ vs control

Edu-positive cells among Linc01234 knockdown OSCC cells were remarkedly lower than those in the control group and siNC group (Fig. 2c), indicating a decreased DNA synthesis ability in OSCC cells with Linc01234 siRNAs. Our data suggested that Linc01234 promotes OSCC cell proliferation by enhancing DNA synthesis.

\section{Linc01234 knockdown inhibits migration and invasion in OSCC cells}

In view of the strong association of Linc01234 expression with lymph node metastasis ( $\mathrm{N}$ stage), the effect of Linc01234 on cell migration and invasion in OSCC cells was further explored. As shown in Fig. 3a and b, a large number of CAL27 and SCC25 cells in the control and siNC groups migrated to the lower surface of the upper chamber. However, a smaller number of OSCC cells migrated to the lower surface in the Linc01234 knockdown groups. Figure $3 \mathrm{c}$ and $\mathrm{d}$ indicate that the wound healing area of the control and siNC groups was significantly greater than that in the Linc01234 knockdown group. These observations indicated that Linc01234 may function as a positive regulator of cell metastasis in OSCC.

\section{Linc01234 sponges miR-433-3p in OSCC cells}

Numerous studies have reported that lncRNAs can act as microRNA (miRNA) sponges, to regulate the biding of endogenous miRNAs to target mRNAs and inhibit the expression of the target mRNAs [16]. First, we found that Linc01234 was mainly expressed in the cytoplasm of CAL27 and SCC25 cells by RT-qPCR (Fig. 4a). Then, we screened the potential target miRNAs using LncBase Predicted version (v.)2 of DIANA tools and obtained 35 potential miRNAs. Screening the Pubmed database, we determined that miR-433-3p, a well-known tumor suppresser, was a possible downstream target of Linc01234 (Fig. 4b). Furthermore, miR-433-3p was decreased in OSCC samples compared with normal tissues, as analyzed by RT-qPCR and the starBase database (Fig. 4c). Then, we performed a dual-luciferase assay to validate this hypothesis. Our results indicated that the miR-433-3p mimics + Linc01234 wild-type (Linc01234 wild) group but not the miR-433-3p mimics + Linc01234 mutant type (Linc01234 mutant) group shown obviously reduced luciferase activity in OSCC cells (Fig. 4d). Additionally, Linc01234 inhibition significantly increased miR-433-3p expression levels in CAL27 and SCC25 cells (Fig. 4e). In summary, we confirmed that Linc01234 could sponge miR-433-3p in OSCC cells.

miR-433-3p directly binds to the 3'UTR of PAK4

We confirmed that Linc01234 served as an oncogene in OSCC progression and demonstrated that Linc01234 functioned as a ceRNA regulating miR-433-3p expression. Thus, we further investigated the potential target of the Linc01234/miR-433-3p axis. Using the TargetScan and starBase tools, we found that the expression of PAK4 was positively correlated with Linc01234, but negatively correlated with miR-433-3p, and miR-433-3p 


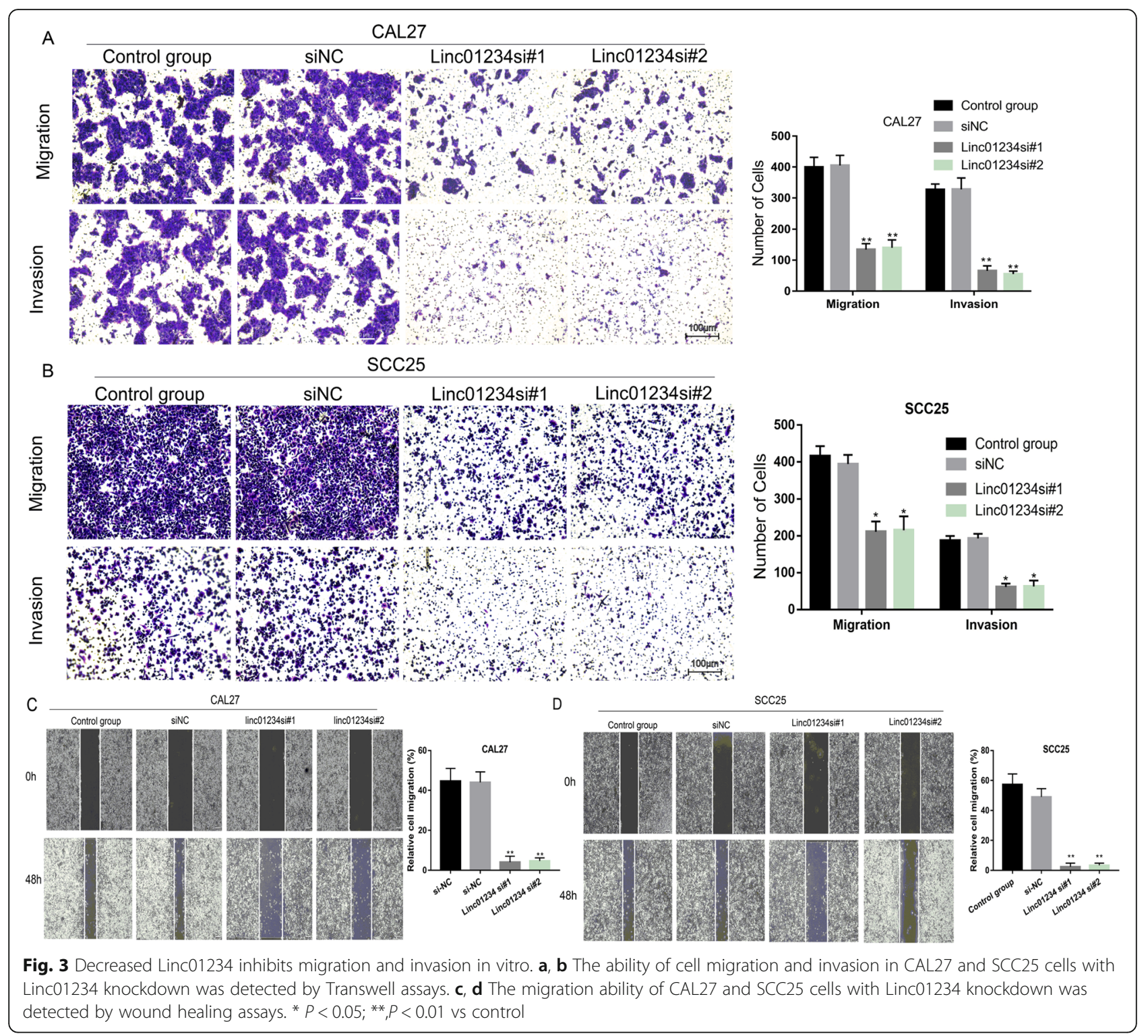

have binding sites in the 3'UTR of PAK4. In addition, PAK4 was remarkedly downregulated in head and neck cancer analyzed by starBase (Fig. 5a-d). Moreover, we compared the endogenous expression of miR-433-3p and PAK4 in different cell lines. The RT-qPCR and WB results indicated an opposite expression pattern between miR-433 and PAK4 in the different OSCC cells (Additional file 2: Figure S2). To confirm whether PAK4 was a direct target of miR-433-3p, we purchased wild-type and mutant luciferase reporter plasmids containing the complementary sequence of miR-433-3p in PAK4 and cotransfected miR-433-3p mimics and these luciferase reporter vectors into OSCC cells. The results indicated that the luciferase activities dramatically declined in OSCC cells cotransfected with miR-433-3p mimics and the wild-type PAK4 vector, but no change in luciferase activity of OSCC cells transfected with the mutant PAK4 plasmid (Fig. 5f). Furthermore, PAK4 expression was significantly suppressed by miR-433-3p overexpression or Linc01234 inhibition in CAL27 and SCC25 cells (Fig. 5e, Additional file 1: Figure S1). PAK4 knockdown also obviously repressed the migration and invasion of OSCC cells (Additional file 3: Figure S3). Therefore, we propose that PAK4 is a direct target of miR-433-3p in OSCC cells.

\section{Discussion}

Recently, increasing evidence has demonstrated that an aberrant lncRNA could facilitate the development and progression of solid tumors and particular lncRNA was identified as an independent biomarker [17-19]. Due to the unknown biological functions of lncRNAs and limited understanding of the molecular mechanisms, more 


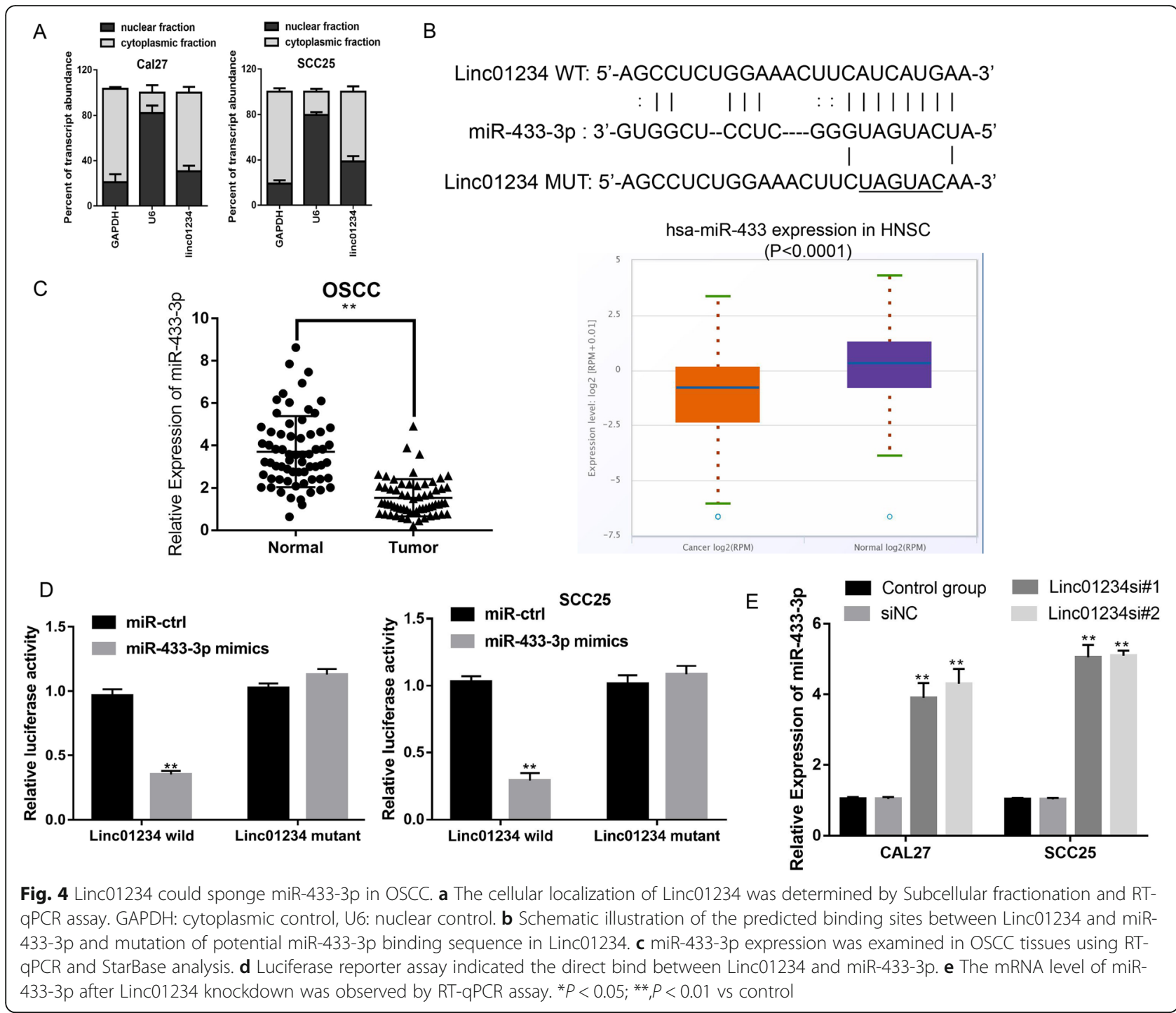

studies are needed. Our present study investigated the OSCC prognosis-related lncRNA---Linc01234, and elucidated its functional roles in OSCC progression.

In the present research, we found that Linc01234 was significantly upregulated in clinical OSCC samples and cell lines. High Linc01234 expression was positively related to advanced $\mathrm{T}$ stage, lymph node metastasis and poor pathological differentiation. In addition, OSCC patients with high Linc01234 expression had a worse overall survival (OS) than patients with low Linc01234 expression based on database analysis. Cox analysis also indicated that Linc01234 expression could be an independent predictor of OSCC patient prognosis as well as $\mathrm{T}$ stage, $\mathrm{N}$ stage and advanced pathological stage. In biological functional experiments, Linc01234 inhibition prominently contributed to the decreased proliferative activity and metastasis of CAL27 and SCC25 cells. In summary, our results suggested that Linc01234 plays a cancer-promoting role in cell growth and metastasis in OSCC.

Growing evidence indicates that lncRNAs and mRNAs can cross-regulate each other by competing for shared miRNA response elements (MREs) [16, 20]. Specifically, many lncRNAs act as sponges in the regulation of miRNA target genes involved in OSCC carcinogenesis $[21,22]$. miR-433, a well-characterized miRNA, was found to be a tumor suppressor in different neoplasms $[23,24]$. Furthermore, Wang et al. reported that miR433 was downregulated in OSCC tissues and demonstrated that miR-433 expression markedly suppressed cell proliferation, invasion and migration by targeting HDAC6 [25]. In our study, we found that Linc01234 contained miRNA response elements for miR-433-3p with $13 \mathrm{nt}$ complementary sequence. Dual-luciferase assays confirmed a direct correlation between miR-433-3p and Linc01234. RT-qPCR results shown that Linc01234 


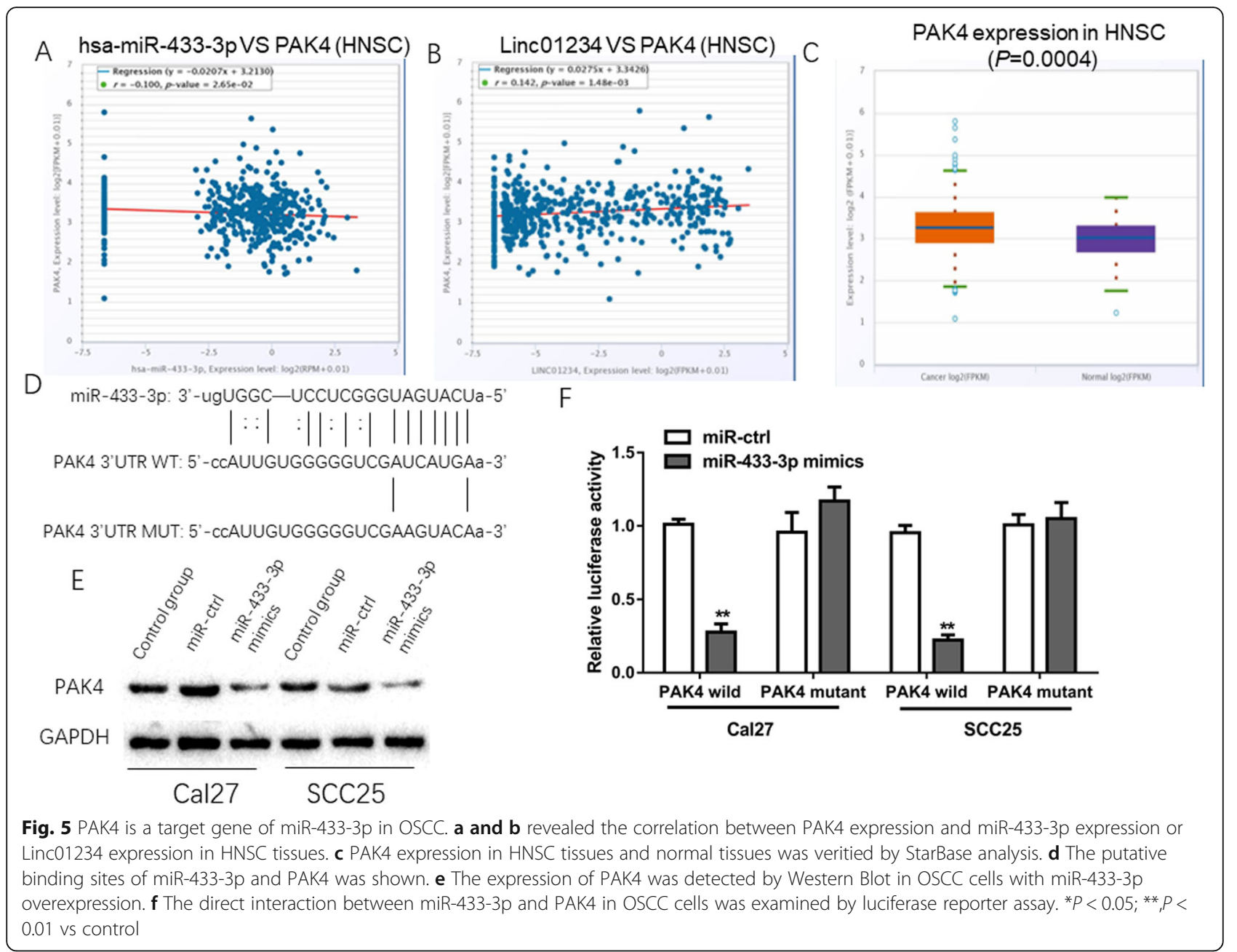

silencing increased the expression levels of miR-433-3p, which was dramatically downregulated in head and neck cancer tissues. Our data suggested that Linc01234 may act as a ceRNA (competing endogenous RNA) of miR433-3p to relieve the repressive effect of miR-433-3p on its target. However, the underlying mechanism of the Linc01234/miR-433-3p axis in OSCC remains unclear.

p21-Activated kinase 4 (PAK4), a member of the PAK family, regulates a wide range of cellular functions, including cell adhesion, migration, proliferation, and survival [26, 27]. Previous studies have reported that dysregulation of PAK4 expression contributes to the development and progression of various tumors $[28,29]$. Several studies have reported that PAK4 could be regulated by many miRNAs in various cancers, including miR-485 and miR-199a-3p [30-32]. In OSCC, PAK4 serves as a super enhancer-associated candidate oncogene and promotes the proliferation of OSCC cells [33]. In our study, we identified PAK4 as a potential target of miR-433-3p based on TargetScan and starBase prediction analyses. Dual-luciferase assays confirmed that miR-433-3p could bind to PAK4 directly. Furthermore, PAK4 protein levels in CAL27 and SCC25 cells with overexpressing miR433-3p were significantly inhibited. Overall, our findings suggest that Linc01234 modulates OSCC carcinogenesis through miR-433-3p-regulated PAK4.

\section{Conclusion}

In summary, our study confirmed that Linc01234 promotes OSCC progression through the Linc01234/miR-433-3p/ PAK4 axis and may serve as a new diagnostic marker or target for the treatment of OSCC patients.

\section{Supplementary information}

Supplementary information accompanies this paper at https://doi.org/10 1186/s12885-020-6541-0.

Additional file 1: Figure S1. Linc01234 knockdown inhibits PAK4 expression. The relative expression of PAK4 was detected with RT-qPCR(A) and Western Blot(B) when CAL27 and SCC25 cells were transfected with siNC, Linc01234 si\#1 or Linc01234 si\#2. ${ }^{*} P<0.05$; ${ }^{*}, P<0.01$ vs control.

Additional file 2: Figure S2. The endogenous expression of miR-433$3 p$ and PAK4 in different cell lines. (A) The endogenous expression of miR-433-3p was examined in OSCC and NOK cells via RT-qPCR assays. (B 
and C) The expression of PAK4 was examined in OSCC and NOK cells via RT-qPCR and Western Blot. ${ }^{*} P<0.05 ;{ }^{* *}, P<0.01$ vs control.

Additional file 3: Figure S3. PAK4 knockdown inhibits migration and invasion in OSCC cells. The relative expression of PAK4 was detected with RT-GPCR(A) and Western Blot(B) when CAL27 and SCC25 cells were transfected with siNC, PAK4 sit\#1 or PAK4 sil\#2. (C) The ability of cell migration and invasion in CAL27 and SCC25 cells with PAK4 knockdown was detected by Transwell assays. ${ }^{*} P<0.05 ;{ }^{*}, P<0.01$ vs control.

Additional file 4: Figure $\mathbf{S 4}$. is the result of mycoplasma contamination detection.

\section{Abbreviations}

ceRNA: Competitive endogenous RNA; HDAC6: Histone Deacetylase 6; LncRNA: Long non-coding RNA; MRE: mirna response element; NOK: Normal oral keratinocytes; OS: Overall survival; OSCC: Oral squamous cell carcinoma; PAK4: P21-Activated kinase 4

\section{Acknowledgements}

The authors thank the cancer research institute of Central South University for its support.

The manuscript does not contain any individual person's data.

\section{Authors' contributions}

$\mathrm{DL}$ and RZ carried out the functional experiments in vitro; YW collected the OSCC tissues and examined the mRNA and protein expression. DL, PX, RZ and $\mathrm{XJ}$ wrote the manuscript. All the authors contributed to the design of the project. All the authors have read and approved the manuscript.

\section{Funding}

The design of our study and collection, analysis, and interpretation of data and writing of this manuscript was supported by the grant of the National Natural Scientific Foundation of China (no: 81260166).

\section{Availability of data and materials}

The datasets used and/or analyzed during the current study are available from the corresponding author on request.

\section{Ethics approval and consent to participate}

The study was approved by the Ethics Committee of Affiliated Haikou Hospital and Xiang-ya Hospital. The informed consent forms were obtained from the OSCC patients. All cell lines used in this study was approved by the Ethics Committee of Affiliated Haikou Hospital and Xiang-ya Hospital.

\section{Consent for publication}

Not applicable.

\section{Competing interests}

The Authors declare no conflicts of interest.

\section{Author details}

'Department of Oral and Maxillofacial Surgery, Affiliated Haikou Hospital, Xiangya Medical College, Central South University, Haikou 570208, China. ${ }^{2}$ Department of Oral and Maxillofacial Surgery, Xiangya Hospital, Central South University, Changsha 410008, China. ${ }^{3}$ Cancer Research Institute, Central South University, Changsha 410008, China.

\section{Received: 19 July 2019 Accepted: 14 January 2020}

\section{Published online: 10 February 2020}

\section{References}

1. Siegel RL, Miller KD, Jemal A. Cancer statistics, 2019. CA Cancer J Clin. 2019; 69(suppl 12):7-34.

2. Siegel RL, Miller KD, Jemal A. Cancer statistics, 2017. CA Cancer J Clin. 2017; 67:7-30.

3. Xie SL, Fan S, Zhang SY, Chen WX, Li QX, et al. SOX8 regulates cancer stemlike properties and cisplatin-induced EMT in tongue squamous cell carcinoma by acting on the Wnt/ $\beta$-catenin pathway. Int J Cancer. 2018;142: 1252-65.
4. Dai J, Mu JW, Mu H. Long non-coding RNA CRNDE regulates cell proliferation, migration, invasion, epithelial-mesenchymal transition and apoptosis in oral squamous cell carcinoma. Oncol Lett. 2019;17:3330-40.

5. Bhan A, Soleimani M, Mandal SS. Long noncoding RNA and Cancer: a new paradigm. Cancer Res. 2017;77:3965-81.

6. Gomes CC, De Sousa SF, Calin GA, Gomez RS. The emerging role of long noncoding RNAs in oral cancer. Oral Surg Oral Med Oral Pathol Oral Radiol. 2017;123:235-41.

7. Zhang C, Bao C, Zhang X, Lin X, Pan D, et al. Knockdown of IncRNA LEF1AS1 inhibited the progression of oral squamous cell carcinoma (OSCC) via hippo signaling pathway. Cancer Biol Ther. 2019;14:1-10.

8. Liu Z, Wu C, Xie N, Wang P. Long non-coding RNA MEG3 inhibits the proliferation and metastasis of oral squamous cell carcinoma by regulating the WNT/ $\beta$-catenin signaling pathway. Oncol Lett. 2017;14:4053-8.

9. Tong J, Ma X, Yu H, Yang J. SNHG15: a promising cancer-related long noncoding RNA. Cancer Manag Res. 2019;11:5961-9.

10. Lin C, Zhang Y, Chen Y, Bai Y, Zhang Y. Long noncoding RNA LINC01234 promotes serine hydroxymethyltransferase 2 expression and proliferation by competitively binding miR-642a-5p in colon cancer. Cell Death Dis. 2019;10:137.

11. Chen X, Chen Z, Yu S, Nie F, Yan S, et al. Long noncoding RNA LINC01234 functions as a competing endogenous RNA to regulate CBFB expression by sponging miR-204-5p in gastric Cancer. Clin Cancer Res. 2018;24:2002-14.

12. Ghaffar M. Khodahemmati s, LI J, Shahzad M, Wang M et al. long noncoding RNA LINC01234 regulates proliferation, invasion and apoptosis in esophageal Cancer cells. J Cancer. 2018;9:4242-9.

13. Gu J, Li Y, Fan L, Zhao Q, Tan B, et al. Identification of aberrantly expressed long non-coding RNAs in stomach adenocarcinoma. Oncotarget. 2017;8: 49201-16.

14. Guo W, Wang Q, Zhan Y, Chen X, Yu Q, et al. Transcriptome sequencing uncovers a three-long noncoding RNA signature in predicting breast cancer survival. Sci Rep. 2016;6:27931.

15. Xie S, Yu X, Li Y, Ma H, Fan S, et al. Upregulation of IncRNA ADAMTS9-AS2 promotes salivary adenoid cystic carcinoma metastasis via PI3K/Akt and MEK/Erk signaling. Mol Ther. 2018;26:2766-78.

16. Zhang S, Ma H, Zhang D, Xie S, Wang W, et al. LncRNA KCNQ1OT1 regulates proliferation and cisplatin resistance in tongue cancer via miR211-5p mediated Ezrin/Fak/Src signaling. Cell Death Dis. 2018;9:742.

17. Fan CN, Ma L, Liu N. Comprehensive analysis of novel three-long noncoding RNA signatures as a diagnostic and prognostic biomarkers of human triple-negative breast cancer. J Cell Biochem. 2019;120:3185-96.

18. Liang S, Zhang S, Wang P, Yang C, Shang C, et al. LncRNA, TUG1 regulates the oral squamous cell carcinoma progression possibly via interacting with Wnt/ $\beta$-catenin signaling. Gene. 2017;608:49-57.

19. Wang $X$, Lu X, Geng Z, Yang G, Shi Y. LncRNA PTCSC3/miR-574-5p governs cell proliferation and migration of papillary thyroid carcinoma via Wnt/ $\beta$ catenin signaling. J Cell Biochem. 2017;118:4745.

20. Liu Y, Du Y, Hu X, Zhao L, Xia W. Up-regulation of ceRNA TINCR by SP1 contributes to tumorigenesis in breast cancer. BMC Cancer. 2018;18(1):367.

21. Li S, Chen X, Liu X, Yu Y, Pan H, et al. Complex integrated analysis of IncRNAsmiRNAs-mRNAs in oral squamous cell carcinoma. Oral Oncol. 2017;73:1-9.

22. Hong $Y$, He H, Sui W, Zhang J, Zhang S, et al. Long non-coding RNA $\mathrm{H} 1$ promotes cell proliferation and invasion by acting as a ceRNA of miR-138 and releasing EZH2 in oral squamous cell carcinoma. Int J Oncol. 2018;52:901-12.

23. Zhang $T$, Jiang $K$, Zhu X, Zhao G, Wu H, et al. miR-433 inhibits breast cancer cell growth via the MAPK signaling pathway by targeting Rap1a. Int J Biol Sci. 2018;14:622-32.

24. Hu X, Wang J, He W, Zhao P, Ye C. MicroRNA-433 targets AKT3 and inhibits cell proliferation and viability in breast cancer. Oncol Lett. 2018; 15:3998-4004.

25. Wang XC, Ma Y, Meng PS, Han JL, Yu HY. miR-433 inhibits oral squamous cell carcinoma (OSCC) cell growth and metastasis by targeting HDAC6. Oral Oncol. 2015;51:674-82

26. Won SY, Park JJ, Shin EY, Kim EG. PAK4 signaling in health and disease: defining the PAK4-CREB axis. Exp Mol Med. 2019;51:11.

27. Park JJ, Park MH, oh EH, Soung NK, Lee SJ, et al. The p21-activated kinase 4slug transcription factor axis promotes epithelial-mesenchymal transition and worsens prognosis in prostate cancer. Oncogene. 2018;37:5147-59.

28. Thillai K, Sarker D, Wells C. PAK4 pathway as a potential therapeutic target in pancreatic cancer. Future Onco. 2018;14:579-82. 
29. Rane CK, Minden A. P21 activated kinase signaling in cancer. Semin Cancer Biol. 2019;54:40-9.

30. Zeng B, Shi W, Tan G. MiR-199a/b-3p inhibits gastric cancer cell proliferation via down-regulating PAK4/MEK/ERK signaling pathway. BMC Cancer. 2018;18(1):34.

31. Callegari E, D'Abundo L, Guerriero P, Simioni C, Elamin BK, et al. miR-199a$3 p$ modulates MTOR and PAK4 pathways and inhibits tumor growth in a hepatocellular carcinoma transgenic mouse model. Mol Ther Nucleic Acids. 2018;11:485-93.

32. Mao K, Lei D, Zhang H, You C. MicroRNA-485 inhibits malignant biological behaviour of glioblastoma cells by directly targeting PAK4. Int J Oncol. 2017; 51:1521-32.

33. Jiang YY, Lin DC, Mayakonda A, Hazawa M, Ding LW, et al. Targeting superenhancer-associated oncogenes in oesophageal squamous cell carcinoma. Gut. 2017;66:1358-68.

\section{Publisher's Note}

Springer Nature remains neutral with regard to jurisdictional claims in published maps and institutional affiliations.

Ready to submit your research? Choose BMC and benefit from:

- fast, convenient online submission

- thorough peer review by experienced researchers in your field

- rapid publication on acceptance

- support for research data, including large and complex data types

- gold Open Access which fosters wider collaboration and increased citations

- maximum visibility for your research: over $100 \mathrm{M}$ website views per year

At BMC, research is always in progress.

Learn more biomedcentral.com/submissions 